\title{
Improving child health services in the UK: insights from Europe and their implications for the NHS reforms
}

Several readers wrote to us to express their concern about the image the $B M J$ chose to accompany this Analysis article by Ingrid Wolfe and colleagues (BMJ 2011;342:d1277, doi:10. 1136/bmj.d1277) in the print issue of 23 April (page 903). It showed a metered dose inhaler being administered to an infant without use of a spacer. According to the British Guideline on the Management of Asthma, for children aged 0-5 years, a metered dose inhaler with a spacer would the preferred delivery method for inhaled drugs.

Cite this as: $B M J 2011 ; 342: \mathrm{d} 2783$ 